$\xi=-1$

\title{
Development of an electric screwdriver with incorporated torque measuring device
}

\author{
Stanley Okiy ${ }^{1}$, Eyere. Emagbetere ${ }^{2 *}$, Benjamin U. Oreko ${ }^{2}$ \\ ${ }^{1}$ Department of Welding Engineering and Offshore Technology, Petroleum Training Institute Effurun, Nigeria \\ ${ }^{2}$ Department of Mechanical Engineering, Federal University of Petroleum Resources Effurun, Nigeria \\ *Corresponding author E-mail: emagbetere.eyere@fupre.edu.ng
}

\begin{abstract}
The use of manual screwdriver is labor intensive and time consuming in some specific engineering work. Information on driving torques of screwdrivers for some common building materials is sparse, despite its relevance. In this work, a portable electric powered screwdriver with an incorporated torque measuring device was developed and then used to assess the driving torques of a locally made brick, Rubber wood and Abura wood. A black phosphate flat-head Phillips slotted screw, Phillips pan head brass coated screws, Phillips hexagonal head with washer brass coated and a Steel sheet metal screw combination Phillips-slotted drive were selected for the investigations. The screwdriver was used to access the drive torques for the selected materials. From the result, it was observed that the driving torque was not significantly affected by the type of material, screw type and screw size. However, the effect of the type of screw head on drive torques was significant.
\end{abstract}

Keywords: Abura Wood; Brick; Bush Rubber; Electric Screwdriver; Torque Measuring Device.

\section{Introduction}

The technique of tightening and loosening fasteners and screws is a major operation in the furniture making processes. This operation can be achieved by using manual or an electric/automatic screwdriver. Ergonomically, the effect of screwdriver and subjects or users applied force and its application has been studied [1-5]. The relationship between user applied torque and screwdriver bit design was analyzed by [6]. In their study, they observed that Phillips bit design might allow users to exert less axial force, which would result in a higher biomechanical effort ratio. Relatedly, the impact of hand tools during fastening processes on subjects has been investigated [7-10]. There several types of electric and automatic screw drivers which have been designed and developed [11-15]. Some of the electric screwdrivers have incorporated torque limiting clutches. Information on the maximum torques needed to drive screws into different materials can be useful for designing torque limiting clutches [16-17]. The ergonomic design of devices for driving torques in different material types could ease forearm musculoskeletal work-oriented injuries, in a highly repetitive manual task. However, locally developed electric screwdrivers in Nigeria do not have components that can be used to measure the driving torques for different materials and screw types. Hence, the aim of this study is to develop an electric powered screwdriver with an incorporated torque measuring sensor capable of fasten some selected screws on common furniture materials and bricks in Nigeria.

\section{Materials and method}

The selection of the various materials for the construction of the electric screwdriver was based on strength, corrosion resistance, wear resistance, cost, use of standard part for ease of replacement, safety of operator [18]. The electric screwdriver consists of two major parts namely; the drive unit, and the control unit.

\subsection{The drive unit}

The drive unit is responsible for screw rotation. The major components of this unit are: electric motor, speed reduction gear, shaft, screw bit and the casing. Description of these components and their functions are as follows:

i) The electric motor: The electric motor aids the rotation of the screw bit. For this study, a 3000rpm, $0.5 \mathrm{~kW}$ (0.67 hp), fancooled motor with [2] poles was selected.

a) Speed of the electric motor

The synchronous speed $(\mathrm{N})$ of the electric motor in revolution per minute is determined using the expression

$\mathrm{N}=\frac{120 \times \mathrm{f}}{\mathrm{p}}$

where, $f$ and $p$ are frequency and number of poles in the motor, respectively.

For $\mathrm{f}=50 \mathrm{~Hz}, \mathrm{p}=2$

$\mathrm{N}=\frac{120 \times 50}{2}=3000 \mathrm{rpm}$ or $0.0873 \mathrm{rad} / \mathrm{s}$

Therefore, the speed of the motor was $3000 \mathrm{rpm}$ or $0.0873 \mathrm{rad} / \mathrm{s}$. b) Maximum torque

The power rating of the motor, $\mathrm{P}=500$ watts; voltage $=230 \mathrm{v}$; speed of the motor, $\mathrm{N}=3000 \mathrm{rpm}$; frequency, $\mathrm{f}=50 \mathrm{~Hz}$.

Using the expression

Torque, $\mathrm{T}=\frac{\text { Power }}{\mathrm{N}}$ 
Where is speed of motor

The maximum torque,

$\mathrm{T} \operatorname{Max}=\frac{500}{0.0873}=5727.38 \mathrm{Nm}$

i) The speed reduction gears: The system has a center distance of $32 \mathrm{~mm}$, a reduction ratio of 20 and input speed of $300 \mathrm{rpm}$.

ii)Shaft: The transmission shaft is connected to the screw bit and aids the rotation. The length of the shaft is $4 \mathrm{~cm}$

iii) Casing: The casing serves as a protective cover and support for the components of the drive unit. It is made of plastic material.

\subsection{The control unit}

The control unit supplies power to the drive unit. It controls the speed, the rotating direction of the screw, measures and displays the drive torque. The block and circuit diagrams of the two units are shown in figures 1 and 2, respectively. The description of parts and their functions are shown in table 1. As shown in the Figure 1, the micro controller $(\mu \mathrm{CU})$ is central to the unit and other components are connected to it. The power supply unit basically supplies power to the system. The power sub-unit has an incorporated step down transformer that reduces the voltage from $220 \mathrm{v}$ to $12 \mathrm{v}$, a bridge rectifier that converts the alternative current, $\mathrm{AC}$ to direct current, DC and a filter capacitor that removes ripples. The power from the power units is then supplied to a voltage regulator that converts the $12 \mathrm{v}$ to $5 \mathrm{v}$ for use by the micro controller which operates on $5 \mathrm{~V}$.

The triode for alternating current (TRIAC) is a three terminal semiconductor device for controlling current [19]. The TRIAC driver unit acts as an interface between the micro controller and the TRIAC. This is because, the TRIAC works with 230v alternative current and the micro controller works with $5 \mathrm{v}$ direct current. The TRIAC is an AC switch. The TRIAC has three terminals: MT1, MT2 and the gate. The neutral is connected to the neutral part of the electric motor and the live is connected to the TRIAC driver unit. When the controller gives a HIGH, the light on the TRIAC driver unit turns on, the gate opens and voltage passes through to the screwdriver.

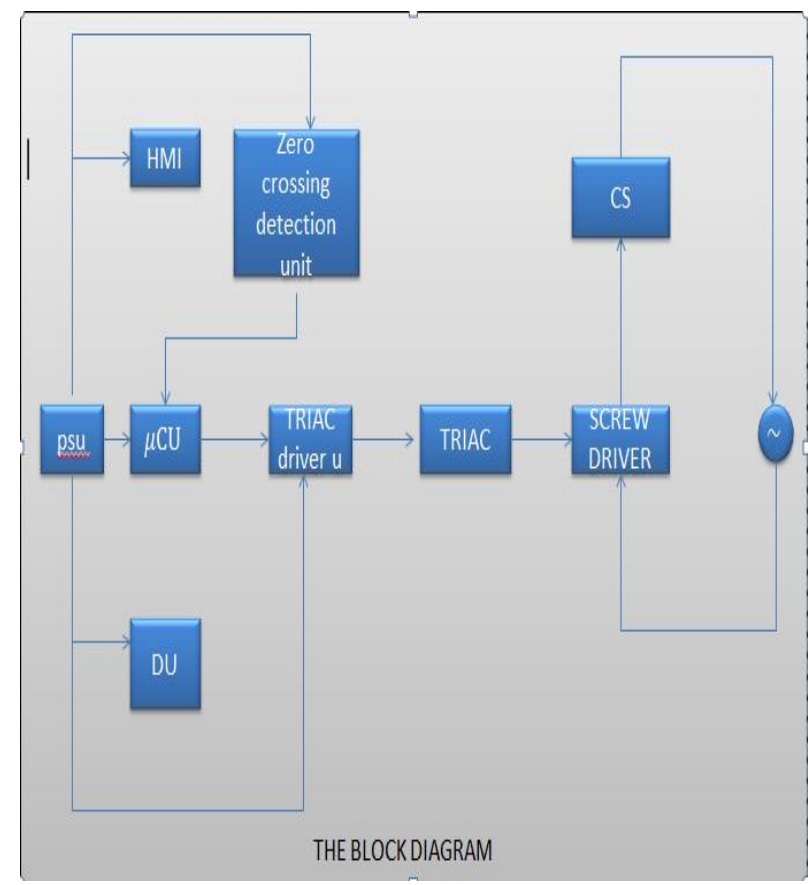

Fig. 1: The Block Diagram for Controller Unit.

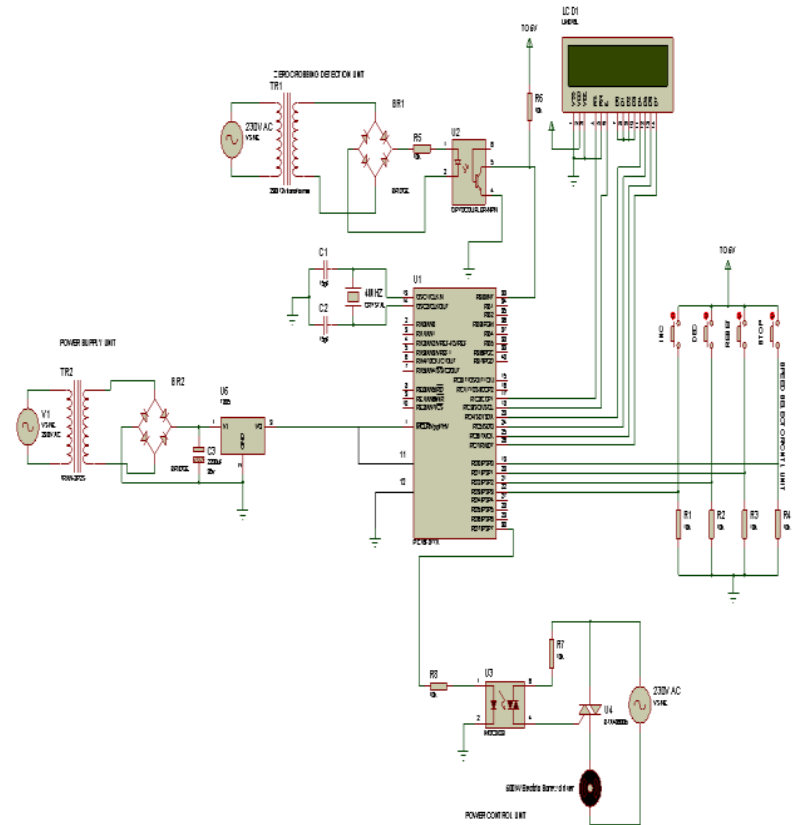

Fig. 1: The Circuit Diagram for Controller Unit.

\subsubsection{Description of selected material}

The drive torques was assessed using for the following materials:

i) Brick: Bricks of size $215 \times 102.5 \times 65 \mathrm{~mm}$

ii) Abura: Abura wood cut into a size of $75 \times 50 \mathrm{~mm}$ for construction purpose was selected

iii) Rubber: Bush rubber wood cut into size of $65 \times 50 \mathrm{~mm}$ was selected for this investigation.

iv) The screws used for the investigations were:

i) Black phosphate flat-head Phillips slotted screw with the following dimensions: Diameter:1.5"; Length: 19mm; Head diameter: 3"

ii)Phillips pan head brass coated screws with the following dimensions: Diameter: 2.5"; Head diameter : 5"; Length: $18 \mathrm{~mm}$

iii) Phillip hex head with washer, brass coated screw

iv) Steel sheet metal screw, zinc plated, pan head, combination Phillips-slotted drive with the following dimensions

a) For the first screw. (screw A)- Diameter: 1.5"; Head diameter: 3"; Length: $12 \mathrm{~mm}$

b) For the second screw. (Screw B)- Diameter: 2"; Head diameter: $4 "$; Length: $12 \mathrm{~mm}$

\subsection{Determination of torque}

The material to be measured was rigidly placed, the power was switch on and the screwdriver connected to the sensor. The voltage level was regulated and the screwdriver was used to screw or drive in the black phosphate flat-head Phillips slotted screw into the brick, rubber wood and Abura wood, respectively. And the torque values were recorded. Due to the programming done on the current sensor, the resulting torque was displayed on the LCD. The same process was repeated for the Phillips pan head brass coated screws, Phillip hex head with washer, brass coated screw and Steel sheet metal screw, zinc plated, pan head, combination Phillips-slotted drive, respectively.

\section{Results and discussion}

Table 2 shows the description and tag for different screw types applied on the selected furniture materials used in the discussion and the presentation of results. Table 3 is the result of ANOVA for the different source of variations, which are the material type, screw type, screw size and head type. As shown, all variations except the type of head has P-values lesser greater than 0.05 . The implication is that the effect of screw types, screw size, material 
type on the torque required to drive a screw is insignificant. The type of head however, has significant effect on the drive torque. This is so because torque is proportional to the radius of turning. Thus a slight change in radial distance of the screw head will significantly affect the drive torques.

Figure 3 shows an average value of the measured drive torque for the different selected materials when the screw 1 and screw 2 were used. Screw 1 and screw 2 are different types but of same size. It was observed that the measured torques tends to be higher when screw 2 was applied to the rubber wood and Abura wood materials, respectively. However, the reverse is the case for bricks material Figure 4 shows the measured drive torque for the three selected materials when screw 3 and screw 4 were used. Screw 3 and Screw 4 are of the same types but have different head design. As observed, the measured torque is higher for screw 4 regardless of the material type. However, the difference in measured torques for both screws is relatively higher for wood materials as compared to the brick material. Figure 5 shows the measured drive torque for the different selected materials when the screw 2 and screw 5 were used. It was observed that the measured torques is higher for screw 5 irrespective of the material type. Higher values drive torques was observed for rubber wood follow by Abura and bricks, respectively. The least drive torques by the brick sample, could be as a result of the low cohesive forces and wear resistant of the bricks as compared to the wooden materials. Although both rubber wood and Abura wood are classified as hard wood, the tensile strength of rubber wood is higher than that of Abura wood. Hence, the higher drive torques observed. Figures 6 to 11 are the pictorial view of the control unit showing the circuit board of the control unit, fan-cooled electric motor, black phosphate flat-head Phillips slotted screw, Phillips pan head brass coated screw, Phillips hex head with washer, brass coated, sheet steel metal screw, zinc plated, pan head, combination Phillips-Slotted drive and the developed screw driver with torque measuring device, respectively.

Table 1: The Components of the Measurement and their Function

\begin{tabular}{|c|c|c|c|c|}
\hline $\mathrm{S} / \mathrm{N}$ & UNIT & PARTS & FUNCTION & QTY \\
\hline \multirow[t]{3}{*}{1} & Power supply unit & $\begin{array}{l}\text { a) } 220 / 12 \mathrm{~V} \text { The step down } \\
\text { transformer }\end{array}$ & It takes the $220 \mathrm{v} / 230 \mathrm{v} \mathrm{AC}$ at $50 \mathrm{~Hz}$ and gives $12 \mathrm{v} \mathrm{AC}$ at $50 \mathrm{~Hz}$. & 1 \\
\hline & & b) b. $1 \mathrm{~N} 4007$ Bridge rectifier & It converts the $12 \mathrm{v}$ AC to $12 \mathrm{v}$ rippled $\mathrm{DC}$ voltage & 1 \\
\hline & & d. 7805 Voltage regulator & It converts the $12 \mathrm{v}$ DC to $5 \mathrm{v}$ DC.suitable for the micro controller & 1 \\
\hline 2 & $\begin{array}{l}\text { The human machine } \\
\text { interface }\end{array}$ & The control buttons & It enables the user operate the system. & 4 \\
\hline \multirow[t]{3}{*}{3} & $\begin{array}{l}\text { The zero crossing } \\
\text { detection unit }\end{array}$ & $\begin{array}{l}\text { a) } 220 / 12 \mathrm{~V} \text { The step down } \\
\text { transformer }\end{array}$ & It takes the $220 \mathrm{v} / 230 \mathrm{v} \mathrm{AC}$ at $50 \mathrm{~Hz}$ and gives $12 \mathrm{v}$ AC at $50 \mathrm{~Hz}$. & 1 \\
\hline & & b. 1N4007 Bridge rectifier & $\begin{array}{l}\text { It converts the } 12 \mathrm{v} A C \text { to } 12 \mathrm{v} \text { DC but with ripples. Hence, the voltage } \\
\text { output is } 12 \mathrm{v} \text { rippled DC }\end{array}$ & 1 \\
\hline & & $\begin{array}{l}\text { c) Zero-crossing detection } \\
\text { circuit }\end{array}$ & Used for voltage control & 1 \\
\hline \multirow[t]{2}{*}{4} & Triac driver unit & a. MOC3021 TRIAC driver & It enables the micro controller drive the screwdriver & 1 \\
\hline & & b) b. BTA41600B TRIAC & $\begin{array}{l}\text { Allows voltage pass through to the screwdriver when the controller } \\
\text { gives a HIGH. }\end{array}$ & 1 \\
\hline 5 & The micro controller & PIC16f877A microcontroller & $\begin{array}{l}\text { a) a. It performs the entire logic of the system. } \\
\text { b) b. Control speed. } \\
\text { c) c. Receives control signal from the HMI. } \\
\text { d) d. Sends status data to the display unit. } \\
\text { e) e. Sends drive signal to TRIAC driver unit which triggers the } \\
\text { TRIAC and drives the screwdriver. }\end{array}$ & 1 \\
\hline 6 & Sensor unit & 30A Hall effect type current sensor & it is used to determine the torque. & 1 \\
\hline 7 & Display unit & $16 \times 2 \mathrm{LCD}$ & $\begin{array}{l}\text { It gives a visual representation of the status of the entire system. It also } \\
\text { enables the user interface the system }\end{array}$ & 1 \\
\hline
\end{tabular}

Table 2: Description and Tag for Different Screw Types Applied on the Selected Furniture Materials

\begin{tabular}{lll}
\hline S/N & Screw tag & Screw Description \\
\hline 1 & Screw 1: & 1.5" Black Phosphate Flat-Head Phillips Slotted Screw \\
2 & Screw 2: & 1.5" Sheet Steel Metal Screw, Zinc Plated, Pan Head, Combination Phillips-Slotted Drive \\
3 & Screw 3: & 2.5" Phillip Hex Head with Washer, Brass Coated Screw \\
4 & Screw 4: & 2.5" Phillips Pan Head Brass Coated Screw \\
5 & Screw 5: & 2" Sheet Steel Metal Screw, Zinc Plated, Pan Head, Combination Phillips-Slotted Drive \\
\hline
\end{tabular}

Table 3: Analysis of Variances (ANOVA) for Different Screw Type, Size and Material

\begin{tabular}{llllll} 
& \multicolumn{2}{c}{ Table 3: Analysis of Variances (ANOVA) for Different Screw Type, Size and Material } \\
\hline Source of Variation & SS & Df & MS & F & P-value \\
\hline Screw type & 0.0082 & 4 & 0.002 & 1.295 & 0.284 \\
Materials & 0.0046 & 2 & 0.002 & 1.101 & 0.3476 \\
Screw size & 31.726 & 5 & 6.345 & 1.024 & 0.41097 \\
Head type & 0.0655 & 5 & 0.013 & 6.583 & $5.20 \mathrm{E}-05$ \\
\hline
\end{tabular}




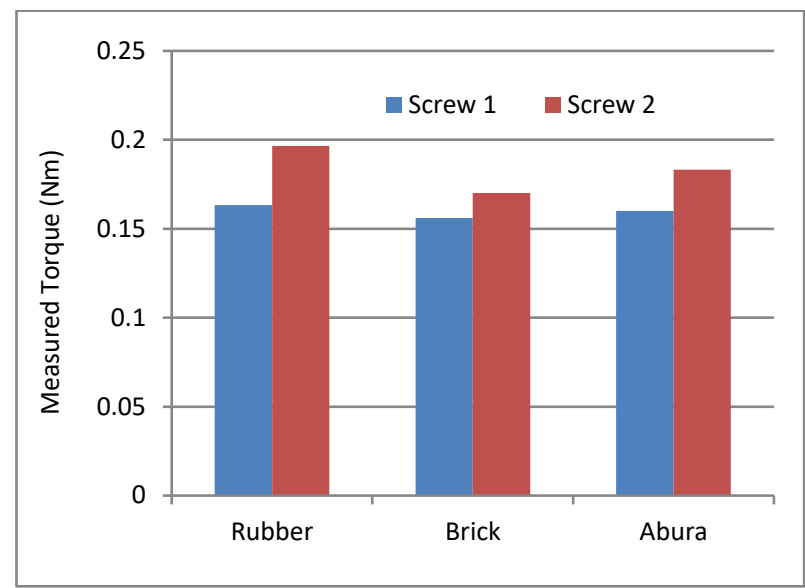

Fig. 2: Measured Torques for Same Size with Different Screw Type.

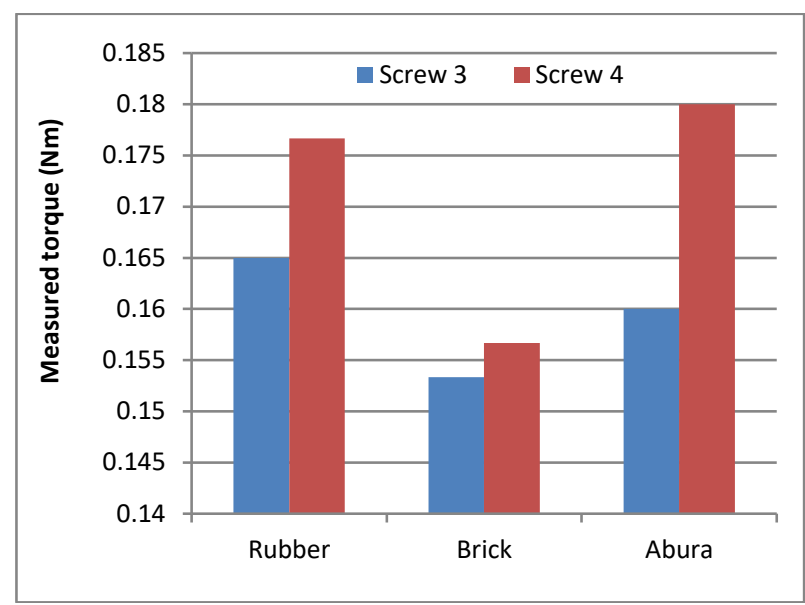

Fig. 3: Measured Torques for Same Screw Types with Different Head Types.

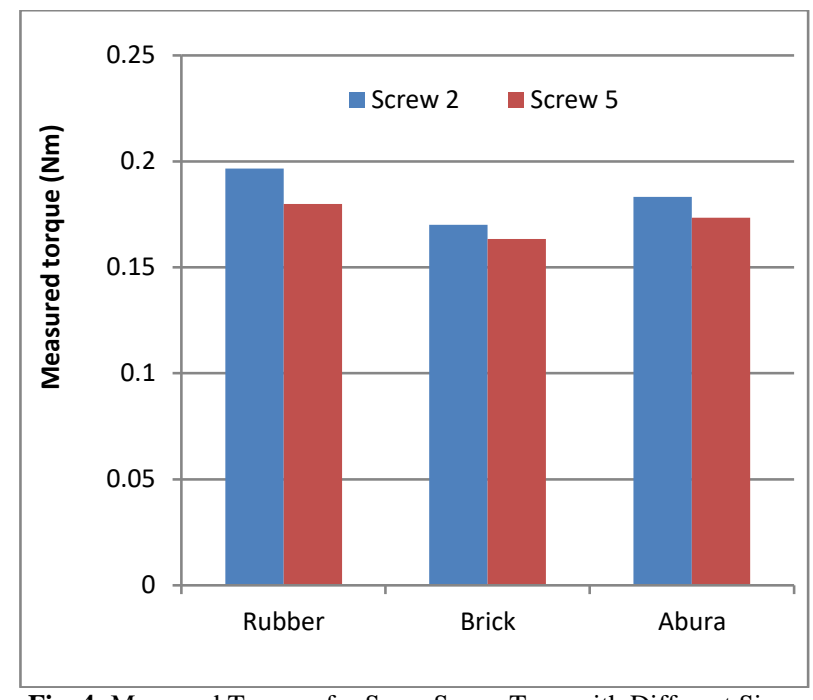

Fig. 4: Measured Torques for Same Screw Type with Different Sizes.
(A) Assembled

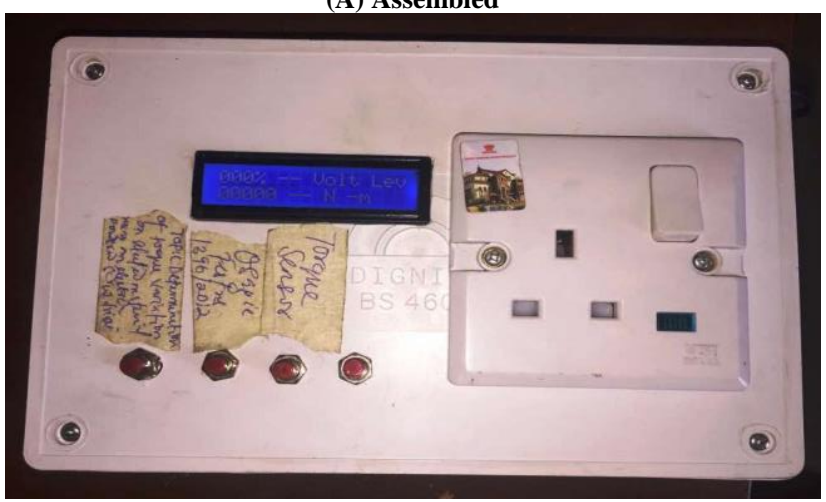

(B) Disassembled

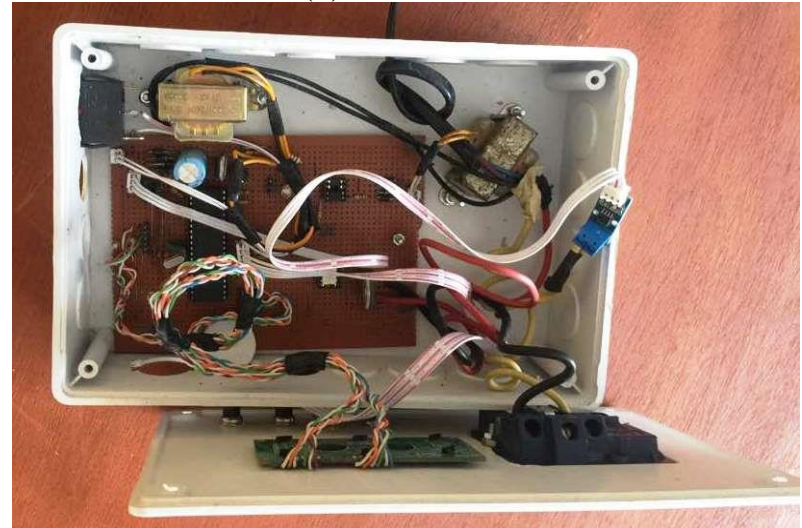

Fig. 5: The Control Unit Showing the Circuit Board of the Control Unit

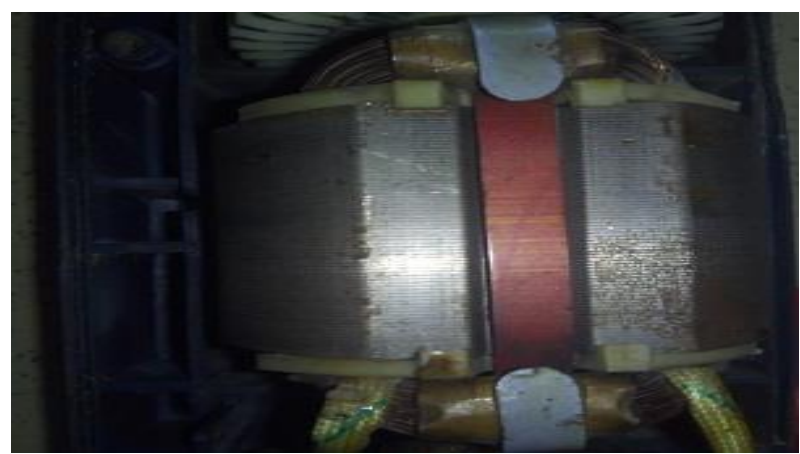

Fig. 7: Fan-Cooled Electric Motor.

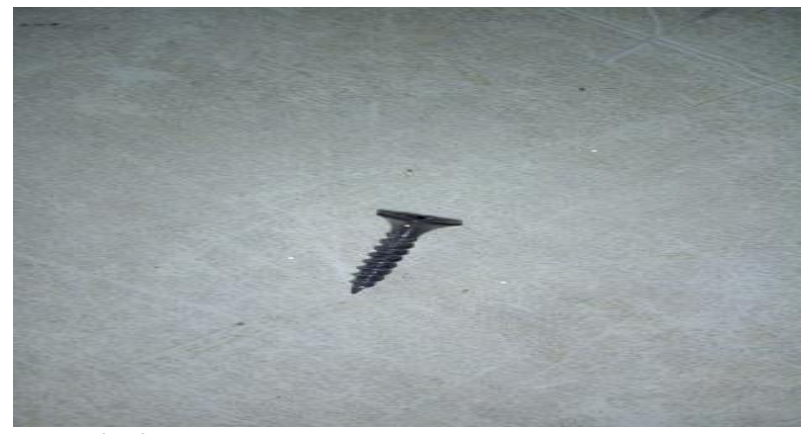

Fig. 8: Black Phosphate Flat-Head Phillips Slotted Screw. 


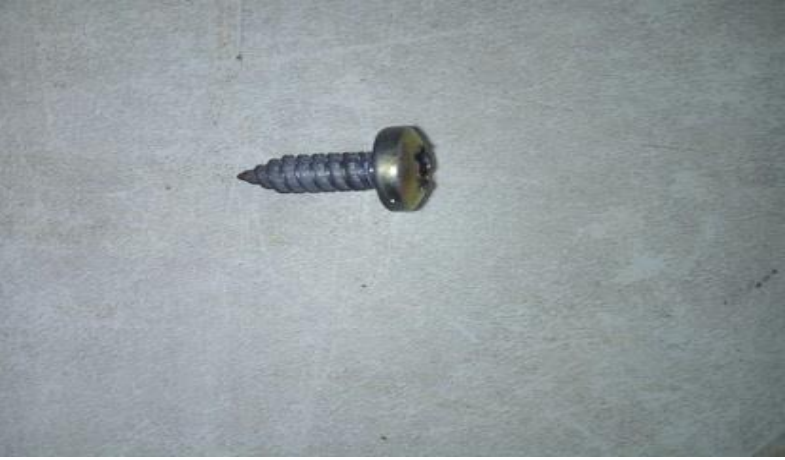

Fig. 9: Phillips Pan Head Brass Coated Screw.

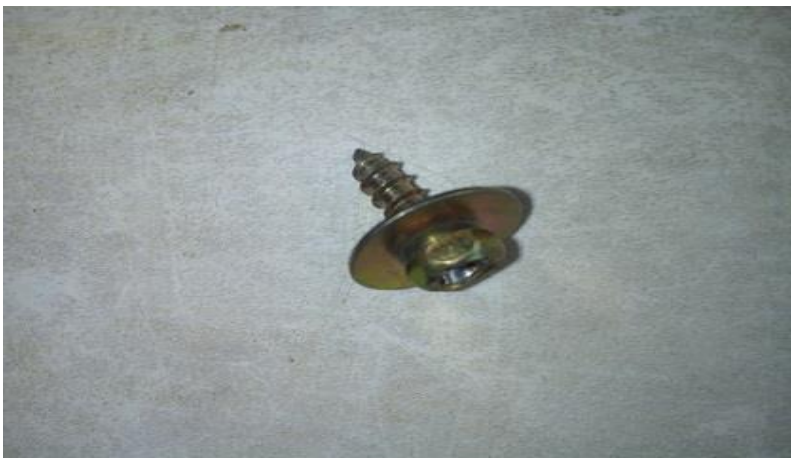

Fig. 10: Phillips Hex Head with Washer, Brass Coated.

(A) 2

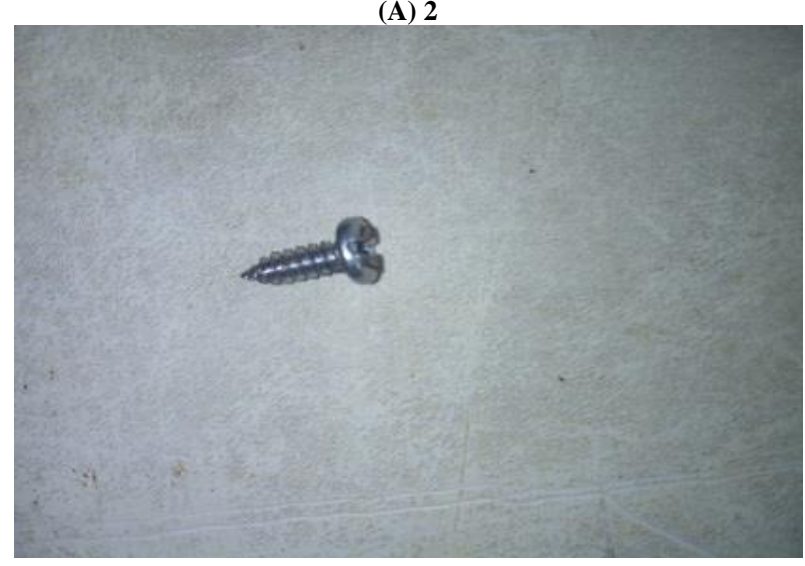

(B) $1.5 \%$

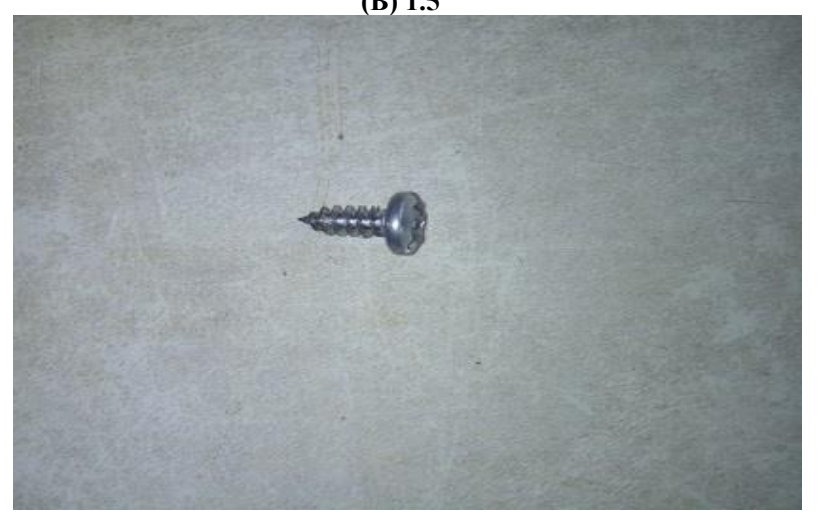

Fig. 11: 2 and 1.5 Inches of Sheet Steel Metal Screw, Zinc Plated, Pan Head, Combination Phillips-Slotted Drive.

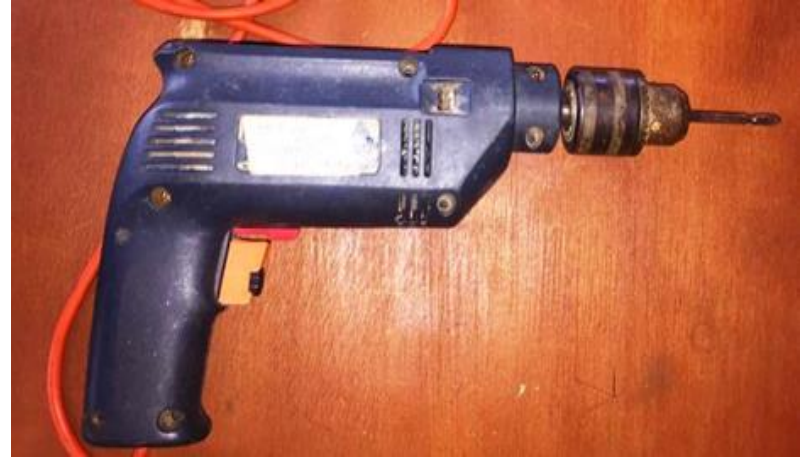

Fig.12: The Developed Screwdriver.

\section{Conclusion}

A 0.5 kilowatts electrical screw driver with incorporated control unit has been developed. The control unit of the screwdriver has incorporated torque sensor which was satisfactorily used to assess the drive torques for rubber wood, Abura wood and bricks materials. The nature of material, screw type and the size of screw do not significantly affect the drive torques during screwing operation. As thus any developed electric screw driver with sufficient capability can be used for screwing operation during furniture making process.

\section{References}

[1] Won-gyu Yoo, Effects of the Different Screwdriver Handle Sizes on the Forearm Muscles Activities and Wrist Motion during Screwdriving Work, J Phys Ther Sci. 2013, 25(7): 885-886. Published online 2013 Aug 20. doi: 10.1589/jpts.25.885. https://doi.org/10.1589/jpts.25.885.

[2] R. Bonfiglioli, S. Mattioli, C. Fiorentini, et al., Relationship between Repetitive Work and the Prevalence of Carpal Tunnel Syndrome in Part-time and Full-time Female Supermarket Cashiers: A Quasi-experimental Study, Int Arch Occup Environ Health, 2007, 80: 248-253, PubMed. https://doi.org/10.1007/s00420-006-0129-0.

[3] L. Punnett, D.H. Wegman, Work-related Musculoskeletal Disorders: The Epidemiologic Evidence and the Debate. J Electromyogr Kinesiol, 2004, 14: 13-23, PubMed. https://doi.org/10.1016/j.jelekin.2003.09.015.

[4] V.M. Ciriello, B.S. Webster, P.G. Dempsey, Maximal Acceptable Torques of Highly Repetitive Screwdriving, Ulnar Deviation, and Handgrip Tasks for 7-hour Workdays, AIHA J (Fairfax, Va), 2002, 63: https://doi.org/10.1080/15428110208984745.

[5] R. Herbert, F. Gerr, J. Dropkin, Clinical Evaluation and Management of Work-Related Carpal Tunnel Syndrome, Am J Ind Med, 2000, 37: 62-74, PubMed. https://doi.org/10.1002/(SICI)10970274(200001)37:1<62::AID-AJIM6>3.0.CO;2-D.

[6] M.D. Hickok, R.W. Marklin, M.L. Nagurka, G. Simoneau, Screwdriver Bit Head Design, Effect of Phillips, Straight, and a Hybrid Design on Torque, Axial Force, and Effort Ratio, Proceedings of the Human Factors and Ergonomics Society Annual Meeting Volume: 58 Issue: 1, (2004) page(s): 1580-1584 H. Sánchez, Effect of a Manual Screwdriver with a Pistol-Grip Handle on Maximum Torque and Muscle Activity, Proceedings of the Human Factors and Ergonomics Society, 52nd Annual Meeting, Sept. 23, 2008, New York, NY

[7] H. Sánchez, Biomechanical Analysis of Screwdriver Handle Designs, Thesis by Héctor Sánchez, (2008) Marquette University, Milwaukee, WI.

[8] H. Sánchez, Biomechanical Analysis of Screw-driver Handle Designs, Thesis by Héctor Sánchez, (2008) Marquette University, Milwaukee, WI

[9] B. Wang, H. Strasser, Left and Right-Handed Screwdriver Torque Strength and Physiological Cost of Muscle Involved in Arm Pronation and Supination. Ergonomics of Manual Work. (1993) 223-226. London: Taylor \& Francis.

[10] P.G. Dempsey, McGorry, O’Brien, W. Raymond, V. Niall, The Effects Of Work Height, Workpiece Orientation,Gender, And Screwdriver Type Of Productivity And Wrist Deviation, International 
Journal of Industrial Ergonomics 33 (2004) 339-346. https://doi.org/10.1016/j.ergon.2003.10.006.

[11] Mountz Torque, Quick Reference Guide for Various Types Electric Torque Screwdriver (2002), Assessed 02/01/2018.

[12] I. Grinevich, V.I. Nikishin, N. Mozga, M.Laitans, The Analysis of Electrical Energy Consumption of the Impact Screwdriver During Assembly of Fixed Threaded Joints, Latvian Journal of Physics and Technical Sciences, Volume 54, Issue 3 (2017) p. 50-57 Online 0868-8257.

[13] W. Rybczynski, One Good Turn: A Natural History of the Screwdriver and the Screw, (2000) ISBN: 978-0-684-86729-8.

[14] S. L. Johnson and L. J. Childress, Ergonomic Effects of Pneumatic Screwdriver Design and Use (Ergonomics Laboratory Report 842). (1984).Industrial Engineering Department Fayetteville, University of Arkansas, SAGE Journals

[15] S. L. Johnson, Evaluation of Powered Screwdriver Design Characteristics, Journal of Human Factor and Ergonomics Society, 1988 Volume 30, Issue 1, pp. 61-69, SAGE Journals https://doi.org/10.1177/001872088803000106.

[16] M. S. Wani1, D. B. Sadaphale, K.A. Patil, Review of Torque Limiter Timer Belt Spindle Drive for Overload Protection, International Journal of Emerging Trends in Science and Technology (IJETST), 2016, Vol.03, Issue 1, Pages 3442-3448, ISSN 2348-9480 https://doi.org/10.18535/ijetst/v3i01.04.

[17] I. Stroe, Design Procedure of Elastic and Safety Clutches using Cam Mechanisms, 12th IFToMM World Congress, Besançon (France), June18-21, 2007.

[18] B.U. Oreko, S. Okiy, E. Emagbetere, M. Okwu, Design and Development of Plantain Fiber Extraction Machine. Nigeria Journal of Technology, NIJOTECH, 2018, Vol. 37, No.2, pp 769 - 804.

[19] www.radio-electronics.com/triac/ what is TRIAC, Assessed $12 / 03 / 2018$ 